\title{
Pneumocystis pneumonia in HIV-negative immunocompromised patients in Internal Medicine ward
}

\author{
Ombretta Para, ${ }^{1}$ Giacomo Zaccagnini, ${ }^{1}$ Lorenzo Corbo, ${ }^{1}$ Filippo Pieralli, ${ }^{2}$ Antonio Mancini, ${ }^{2}$ Valentina Scheggi, ${ }^{3}$ \\ Francesco Tramonte, ${ }^{4}$ Carlo Nozzoli ${ }^{1}$ \\ ${ }^{1}$ Medicina Interna 1, AOU Careggi, Firenze; ${ }^{2}$ Medicina Interna ad Alta Intensità, AOU Careggi, Firenze; ${ }^{3}$ Medicina Interna \\ ad Indirizzo Cardiovascolare e Perioperatorio, AOU Careggi, Firenze; ${ }^{4}$ Medicina Interna e della Complessità, AOU Senese, \\ Siena, Italy
}

\begin{abstract}
Pneumocystis jirovecii pneumonia (PJP) is an opportunistic infection typically observed in AIDS patients, for whom it represents a leading cause of death. However, its incidence among HIV-negative immunocompromised patients is progressively increasing, with a significantly higher mortality compared to that of AIDS-patients. We performed a retrospective observational study on HIV-negative patients with PJP. We aimed to determine their epidemiological features and their biohumoral and therapeutic variables, searching for a correlation between them and our patients' outcome. We included all patients admitted to our Internal Medicine ward from January 2010 to June 2015, who were immunocompromised at the time of admission and had microbiologically confirmed PJP (association between compatible clinical-radiological findings and qualitative polymerase chain reaction positivity on bronchoalveolar lavage). Their immune impairment was assessed considering both their medical history and their complete white blood cells (WBC), differential WBC and their CD4 cell count. Transfer to Intensive Care Unit (ICU) or death was considered as an unfavorable clinical outcome, while hospital discharge or transfer to a non-ICU ward was considered as a favorable outcome. We included a total of 18 patients in our statistical analysis. We used Student's t-test and Fischer's $\chi$-square test to compare, respectively, normally distributed continuous variables and non-continuous variables. Our patients' mean age was $65 \pm 13.9$ years. All of them had cancer, mostly hematological malignancies (13/18), notably non-Hodgkin lymphoma (NHL; 8/13). They were all being or had been recently treated with chemotherapy (10/18) and/or high-dose glucocorticoids, with full dose or during tapering (13/18). Statistical analysis of blood tests results showed a significant difference between mean serum lactate dehydrogenase (LDH) concentration in the group of patients with favorable $v s$ unfavorable outcome. Also, mean serum immunoglobulins $\mathrm{G}(\mathrm{IgG})$ concentration and certain arterial blood gas findings (mean arterial $\mathrm{paO}_{2} / \mathrm{FiO}_{2}$, mean blood $\mathrm{Ph}$ and mean $\mathrm{paCO}_{2}$ ) at the time of admission were significantly different in the two groups of patients. $12 / 18$ patient's outcome turned out unfavorable. Trimethoprim + sulfamethoxazole (TMP+SMX) treatment was given to all our patients, with a mean duration of $13.39 \pm 9.36$ days. Patients with a favorable outcome had received TMP $+\mathrm{SMX}$ treatment significantly earlier than those with an unfavorable outcome. Hematological malignancies, according to literature, confer the strongest predisposition to PJP. Both chemotherapy and high-dose Glucocorticoid treatment are well known predisposing factors. A remarkable elevation of serum LDH represents both a typical clinical feature and a well-known negative prognostic factor in PJP. Low IgG levels have never been reported as a negative prognostic factor, but their role in enhancing macrophage killing of pneumocystis may account for the worst observed prognosis in the group of patients with lower mean levels. Therefore, in order to reduce the heavy mortality rate associated with PJP, an early beginning of specific treatment is of utmost importance, and even if this is certainly true for many infectious diseases, the time gap is particularly limited in the setting of this type of pneumonia. Hence, PJP should

Correspondence: Ombretta Para, Medicina Interna 1, AOU Careggi, Largo Brambilla 3, 50134 Firenze, Italy.

E-mail: ombretta.para@gmail.com

Key words: Pneumocystis pneumonia; hematological maligbe ruled out as soon as possible and, in case of a strong clinical-radiological suspicion, therapy should be started immediately, even while waiting for microbiological confirmation (especially in critically-ill patients).
\end{abstract} nancy; solid organ tumors; treatment; outcomes.

Conflict of interests: the authors declare no conflict of interests.

Received for publication: 24 January 2020.

Accepted for publication: 27 February 2020.

This work is licensed under a Creative Commons Attribution NonCommercial 4.0 License (CC BY-NC 4.0).

${ }^{\circ}$ Copyright: the Author(s), 2020

Licensee PAGEPress, Italy

Italian Journal of Medicine 2020; 14:69-78

doi:10.4081/itjm.2020.1262

\section{Introduction}

Pneumocystis pneumonia (formerly known as Pneumocystis carinii is an opportunistic infection caused by the fungus Pneumocystis jirovecii). This infection, was originally found in malnourished European children during the Second World War, in immunocompromised patients and in critically ill cancer patients, it was later observed in apparently healthy subjects such as homosexual men and intra- 
venous drug abusers in California in 1980. This led to the discovery of the now known HIV infection. ${ }^{1}$ From the 1980s onwards, Pneumocystis jirovecii pneumonia (PJP) has mostly stricken HIV-positive patients as an AIDS-defining condition: in fact, CD4+ cell count $<200 / \mu \mathrm{L}$, or CD4+/Total lymphocytes $<14 \%$, and a history of oropharyngeal candidiasis are the most important predisposing factors and indications for chemoprophylaxis. ${ }^{2-4}$ However, in the last few years, the incidence of this form of pneumonia among HIV-negative immunocompromised patients has remarkably increased, with a significantly higher mortality compared to that of AIDS-patients (30-50\% vs 6.6-17\%). ${ }^{5-11}$ Solid or hematological cancers; recent or ongoing antineoplastic treatment (including hematological stem cell transplant or lymphocyte-depleting antibodies), high-dose Glucocorticoid treatment (even during its tapering) and other immunosuppressive drugs, used to prevent solid organ transplant rejection or to treat autoimmune diseases, are conditions predisposing to PJP in non-HIV patients, and hematological malignancies are correlated to the highest risk. ${ }^{12-17}$ Moreover, while epidemiological features, most accurate diagnostic techniques, prophylaxis indications and most effective therapeutic approaches have been thoroughly characterized by literature for HIV-positive patients, few data and guidelines are currently available for HIV-negative patients, despite the increasing incidence and poor prognosis of PJP in this category of patients. We examined data from all patients admitted to our Internal Medicine ward, from January 2010 to June 2015, with clinical and radiological features suggestive of PJP and a microbiological confirmation, recording their predisposing factors, demographic features, radiological findings, pharmacological and support treatment, duration of hospital stay and intrahospital outcome. We also tried to evaluate CURB-65 and PSI prognostic scores accuracy and searched for arterial blood gas and laboratory findings significantly correlated with our patients' outcome.

\section{Materials and Methods}

We performed an observational retrospective study on 18 consecutive patients admitted to our Internal Medicine ward from January 2010 to June 2015. All of these patients were immunocompromised and HIV-negative (Table 1). We enrolled in the study those patients who, at the time of admission, were complaining of respiratory symptoms and showed clinical signs of pulmonary involvement; their peculiar immune status and their radiological findings raised the suspicion of PJP, and therefore all these patients underwent bronchoscopy with bron- choalveolar lavage (BAL). Although, according to literature, the gold standard to identify Pneumocystis jirovecii remains the microscopical examination of respiratory fluids (especially BAL) with Giemsa or silver methenamine stain, an increasing number of recent clinical studies praised the diagnostic accuracy of polymerase chain reaction (PCR) test, which, in addition, is not influenced by operator's experience. As many other medical centers routinely do, we used PCR test to microbiologically confirm PJP. ${ }^{15-17}$ The concurrent presence of clinical-radiological findings compatible with PJP and qualitativePCR positivity for the aformentioned microorganism was considered a definite diagnostic confirmation and an inclusion criterion for our study. We recorded our patients demographic features (age and sex), predisposing factors reported on clinical history (active solid or hematological neoplastic disease; hematological stem cell transplant; solid organ transplant; recent or ongoing treatment with chemotherapy, rituximab or bortezomib; treatment with high dose Glucocorticoids, even during the tapering phase); CURB 65 and PSI index calculating admittance risks; principal comorbidities; possible ongoing prophylactic treatment of Pneumocystis jirovecii with trimethoprim cotrimoxazole; the findings of radiological chest X-ray OR chest CT upon admittance; the principal qualitative and quantitative PCR test for CMV; Pneumococcal and Legionella urinary antigens; serum Aspergillus galactomannan; intrahospital pharmacological treatment and eventually support treatment with not invasive ventilation; the duration of in-hospital stay will be the outcome, intended as unfavorable: death or transfer to the Intensive care ward. According to literature, it is widely shown especially for immunocompromised HIV-negative patients, that the admission to Intensive care ward is predictive of poor prognosis.

\section{Statistical analysis}

We expressed continuous variables as a mean \pm standard deviation and dichotomous variables as proportions and percentages. Student's $t$-test was used to compare normally distributed continuous variables and Fischer's $\chi$-square test was used to

Table 1. Immune status.

\begin{tabular}{lc}
\hline Parameter & Mean value \\
\hline Total white blood cells count & $5531 \pm 2835$ cells $/ \mu \mathrm{L}$ \\
\hline Lymphocytes count & $533 \pm 512$ cells $/ \mu \mathrm{L}$ \\
\hline CD4+ lymphocytes count & $139 \pm 62$ cells $/ \mu \mathrm{L}$ \\
\hline
\end{tabular}


compare non-continuous variables. We considered results with $\mathrm{P}<0.05$ as statistically significant for determining the clinical outcome. We performed this statistical analysis using IBM SPSS Statistics 20.0 statistical software.

\section{Results}

The results of our statistical analysis of demographic, anamnestic, clinical-radiological, prognostic and therapeutic variables are shown in Tables 1 and 2.

Our patients mean age was $65 \pm 13.9$ years, $14 / 18$ (77.78\%) were male and 4/18 (22.22\%) were females (Table 1). None of the 18 patients was taking prophylaxis at the time of infection. An active neoplastic disease was found in all these individuals $(100 \%)$, $13 / 18$ of which $(72.22 \%)$ had hematological malignancies, notably non-Hodgkin lymphoma (NHL; $8 / 13,61.54 \%)$. Out of the 5 patients $(27.78 \%)$ with solid cancer, only $1 / 5(80 \%)$ had lung cancer. As it is common nowadays among patients admitted to Internal Medicine wards (partly because of their elderly age), many of our patients had more than one comorbidity and, in particular, 6/18 (33.33\%) had three or more comorbidities. Besides pathologic conditions, our patients' other predisposing factors for PJP consisted mainly of recent or ongoing chemotherapy treatments $(10 / 18,55.55 \%)$ and highdose glucocorticoid treatment, with full dose or during tapering $(13 / 18,72.22 \%) .6 / 18$ of our patients $(33.33 \%)$ were taking the anti-CD20 monoclonal antibody rituximab at the time of infection, $1 / 6$ for CLL (16.67\%) and 5/6 for B-cells NHL (83.33\%).

Mean hospital stay was $17.11 \pm 9.23$ days. The patients' outcome turned out to be unfavorable, 12/18 (66.67\%).

The most frequent CURB-65 score was 2 (7/18 patients, $38.89 \%$ ) and the most frequent PSI risk class was IV (11/18 patients, $61.11 \%$ ) (see histogram).
Regarding the main radiological findings, the most represented consisted of X-ray multiple interstitial opacities $(5 / 17,29.41 \%)$ and CT multiple ground glass opacities with pleural effusion (8/17, 47.06\%). 7/17 chest X-rays and 7/17 chest CT-scans showed a diffuse interstitial thickening (isolated or associated with further lesions) (Table 1).

As far as I am concerned, the analytic laboratory data of blood tests results showed a significant difference between mean serum lactate dehydrogenase $(\mathrm{LDH})$ concentration in the group of patients with favorable $v s$ unfavorable outcome $(273.83 \pm 116.07 \mathrm{U} / \mathrm{L}$ vs $561.09 \pm 311.14 \mathrm{U} / \mathrm{L} ; \mathrm{P}<0.05$ ) (Table 2). Mean serum immunoglobulins $\mathrm{G}$ ( $\mathrm{IgG}$ ) concentration too was significantly different in the two groups of patients $(8.685 \pm 5.254 \mathrm{~g} / \mathrm{L}$ for patients whose outcome turned out to be favorable vs $3.401 \pm 1.702 \mathrm{~g} / \mathrm{L}$ for those patients whose outcome turned out to be unfavorable; $\mathrm{P}<0.05$ ). However, our patients' white blood cells differential count (Table 2) showed a mean value of $5531 \pm 2835$ leukocytes $/ \mu \mathrm{L}$ (range: 820 10600 cells $/ \mu \mathrm{L}$ ), despite the fact that the mean leukocytes count falls within the normal range or is only slightly lower than the minimal normal value. Our patients mean lymphocytes count was $533 \pm 512$ cells $/ \mu \mathrm{L}$ (range: $170-1200$ cells $/ \mu \mathrm{L}$ ) and the CD4+ lymphocytes count was $139 \pm 62$ cells/ $\mu \mathrm{L}$ (range: $72-$ 302 cells $/ \mu \mathrm{L}$ ). Those data will confirm the state of immunosuppression of our patients at moment of admission, and their lymphopenia (particularly regarding their CD4+ cells) known as strong predisposing factor for PJP.

There were also significant differences between the two patient groups (favorable $v s$ unfavorable outcome $)$ in mean arterial blood $\mathrm{pH}(7.5 \pm 0.018 v \mathrm{~s}$ $7.42 \pm 0.049 ; \mathrm{P}<0.005)$, mean $\mathrm{paCO}_{2}(32.52 \pm 3.57$ $\mathrm{mmHg}$ vs $39.61 \pm 5.34 \mathrm{mmHg} ; \mathrm{P}<0.05)$ and mean $\mathrm{paO}_{2} / \mathrm{FiO}_{2}(274.6 \pm 88.49$ vs $177.4 \pm 63.67 ; \mathrm{P}<0.05)$ at the time of admission.

Trimethoprim + sulfamethoxazole (TMP+SMX) treatment was given to all our patients, with a mean du-

Table 2. Statistically significant results $(\mathrm{P}<0.05)$.

\begin{tabular}{lcc}
\hline Parameter & $\begin{array}{c}\text { Mean value in patients with } \\
\text { favorable outcome }\end{array}$ & $\begin{array}{c}\text { Mean value in patients with } \\
\text { unfavorable outcome }\end{array}$ \\
\hline Serum $\mathrm{LDH}$ concentration & $273.83 \pm 116.07 \mathrm{U} / \mathrm{L}$ & $561.09 \pm 311.14 \mathrm{U} / \mathrm{L}$ \\
\hline Serum $\mathrm{IgG}$ level & $8.685 \pm 5.254 \mathrm{~g} / \mathrm{L}$ & $3.401 \pm 1.702 \mathrm{~g} / \mathrm{L}$ \\
\hline Admission arterial $\mathrm{PaO}_{2} / \mathrm{FiO}_{2}$ & $274.6 \pm 88.49$ & $177.4 \pm 63.67$ \\
\hline Admission arterial $\mathrm{pH}$ & $7.5 \pm 0.018$ & $7.42 \pm 0.049$ \\
\hline Admission arterial $\mathrm{paCO}_{2}$ & $32.52 \pm 3.57 \mathrm{mmHg}$ & $v s 39.61 \pm 5.34 \mathrm{mmHg}$ \\
\hline Timing of treatment start (days after admission) & $1.17 \pm 1.17$ days & $6.08 \pm 4.38$ days
\end{tabular}


ration of $13.39 \pm 9.36$ days. We found that patients with a favorable outcome had received TMP+SMX treatment significantly earlier than those with an unfavorable outcome (treatment started, on average, $1.17 \pm 1.17$ vs $6.08 \pm 4.38$ days after hospital admission). It is also worth noting that the mean elapsed time (considering all the 18 patients) between hospital admission and treatment start $(4.44 \pm 4.3$ days) was comparable with the mean elapsed time between admission and BAL collection (4.235 \pm 3.78 days), indicating that, on average we started specific treatment as soon as the clinical suspicion of PJP was raised, even if we had not received a PCR confirmation yet. Glucocorticoids (with a therapeutic intent) were administered to $17 / 18$ patients (94.44\%) and caspofungin was administered to 13 out of 18 patients: the outcome turned out to be unfavorable for $12 / 17(70.59 \%)$ and $9 / 13$ patients $(69.23 \%)$ respectively (Figure 1).

\section{Discussion}

Concerning the main characteristics of our patients, we noticed that the mean age was slightly higher than the one reported by other studies concerning PJP in HIV-negative patients (65 vs 44.6-51 years old). ${ }^{18-27}$
The presence of hematological cancer in 13 out of 18 patients $(72.22 \%)$ according to literature, confers a strong predisposition to PJP; in details the majority of our onco-hematologic patients had NHL $(8 / 13,61.54 \%)$.

In these cases, a significant predisposing factor that allowed us to arouse the PCP suspect was the ongoing therapy, chemotherapy, steroids and biological therapy: rituximab and bortezomib. However, in literature the majority of cases of PJP occur in HIVnegative cancer patients receiving chemotherapy or glucocorticoids (in particular within the context of brain or hematological tumors). In the last few decades, monoclonal antibody therapy has been widely and increasingly used to fight cancer and autoimmune diseases. When monoclonal anti-lymphocyte anti-TNF is administered, a common adverse reaction is represented by the immune impairment.

PJP has been observed in patients treated with infliximab, etanercept (anti-TNF $\alpha$ monoclonal antibodies) and alemtuzumab (anti-CD 52 monoclonal antibody causing long-lasting and deep immunosuppression).

The whole biological treatment induces lymphocyte $\mathrm{T}$ depletion or T-helper 1 immune response inactivation: for a long time, CD4+ lymphocytes were considered by researchers to be the most important, if

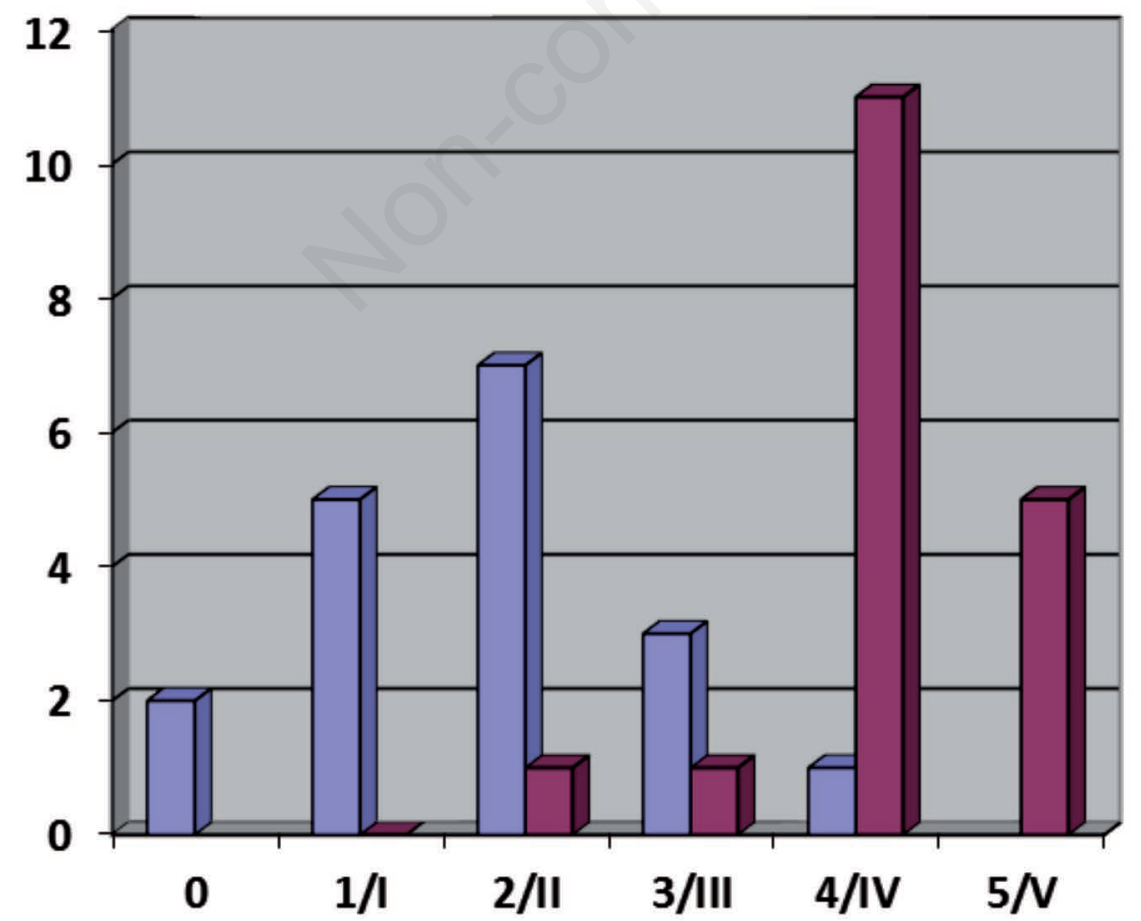

$\square$ CURB-65 口PSI

Figure 1. CURB-65 score was and PSI risk class. 
not the only, immune cells involved in preventing PJP.

However, in vitro studies demonstrate the importance of $\operatorname{IgG}$ and $\operatorname{IgA}$ for enhancing macrophages respiratory burst (the most important reaction for killing Pneumocystis jirovecii) ${ }^{28,29}$ and many cases report of PJP in patients taking rituximab (antiCD20 monoclonal antibody) led to reconsideration of B-lymphocytes protective role. ${ }^{30-40}$ Moreover, $\mathrm{B}$-cells are also able to act as APC for CD4+ lymphocytes.

Therefore, it has been accepted that B-lymphocyte depletion may be, in certain cases, a strong predisposing factor to PJP and, in particular, it may be associated with this infection even in the setting of a CD4+ cell count $200 / \mu \mathrm{L}$.

It is noteworthy that the 6 patients who were taking rituximab at the time of infection had a mean total lymphocyte count of 442 cells $/ \mu \mathrm{L}$, a mean $\mathrm{CD} 4+$ lymphocyte count of 231 cells/ $\mu \mathrm{L}$ and a mean $\mathrm{IgG}$ and $\mathrm{IgM}$ concentration of $4,575 \mathrm{~g} / \mathrm{L}$ and 0.38 $\mathrm{g} / \mathrm{L}$, respectively: such an immune status reflects a total and B-cells lymphocytopenia (also responsible for their hypogammaglobulinemia), with a CD4+ cell count above the cut-off value accountable for the highest risk of PJP.

As for treatment, it was noted that, out of the 13 patients with an anamnestic positivity for high-dose Glucocorticoid, the outcome turned out to be unfavorable for 9 of them $(69.23 \%)$. Therefore, even in the absence of statistical significance given the limited study sample, there is some evidence that may help to formulate the hypothesis that the steroid-related immunosuppression is associated with a poor outcome.

Literature underlines that treatment with highdose glucocorticoids mainly represents a predisposing factor to PCP and not a negative prognostic factor.

However, PJP features a higher degree of inflammation in HIV-negative patients compared to HIVpositives, and there is a substantial agreement among authors on the negative effect of an intense inflammatory reaction on respiratory function, linked from a physiopathological point of view to a parenchymal lung damage.

During the tapering phase of steroidal treatment, associated with a simultaneous and proportional immune reconstitution, PJP is most likely to become clinically evident and, as it is typical of this infection in HIV-negative patients, to show an acute course. It is possible that, due to the sudden awakening of the immune system during the tapering phase, the consequent inflammatory reaction may be so intense as to rapidly lead to respiratory failure, thus may explain why high-dose Glucocorticoid treatment was somewhat correlated to an unfavorable outcome for our patients. A clinical study by Boonsarngsuk et al. appears to support this hypothesis, since it found a statistically significant correlation between previous high-dose Glucocorticoid treatment and an unfavorable outcome. ${ }^{41}$

The analysis of the main laboratory data showed that surviving patients had an average serum concentration of LDH and significantly different IgG compared with deceased.

According to the majority of studies regarding PJP, both in HIV-positive and HIV-negative patients, an elevation in serum LDH concentration is a sign, although non-specific, that helps diagnostic confirmation and it is an important negative prognostic factor, since LDH elevation is a marker of cellular necrosis and an indicator of poor tissue perfusion. $^{42-47}$

Although literature has reported serum $\operatorname{IgG}$ deficit only as a predisposing factor for PJP in HIVpositive patients, ${ }^{48-52} \mathrm{IgG}$ role as opsonizing molecules and enhancer of macrophages respiratory burst (as already mentioned) may account for the worst observed prognosis in the group of patients with a lower mean serum IgG concentration. It is interesting to note that our patients mean serum procalcitonin concentration was $6.24 \pm 10.66 \mathrm{ng} / \mathrm{mL}$, way too high to be related to a fungal infection in general and PJP in particular (PCT is usually below $2 \mathrm{ng} / \mathrm{mL}$ ): this laboratory finding can be explained by some patients positivity to BAL microscopic examination, hemocultures and urinary antigens for Gram + and Grambacteria.

Some of our patients also presented a positive PCR test for cytomegalovirus performed on blood or BAL. CMV is one of the most common etiologic agents of viral pneumonia amongst immunocompromised patients and, given the impairment of lymphocytes and macrophages immune response associated with this infection, it can serve as a predisposing factor for PJP and worsen its prognosis, both in HIVpositive and HIV-negative patients, according to literature. ${ }^{14,41,53,54}$ However, no significant difference concerning the outcome was noted in patients with multiple microbiological positivity.

Literature reports that perihilar, bilateral CT ground-glass opacities or X-ray interstitial opacities (both frequently observed in our patients) and diffuse interstitial thickening represent typical radiological features of the PJP.

The analysis of blood gas results, noted significant differences in the average arterial $\mathrm{pH}$ levels, mean $\mathrm{paCO}_{2}$ and average $\mathrm{PaO}_{2} / \mathrm{FiO}_{2}$ ratio upon admission.

The admission $\mathrm{PaO}_{2} / \mathrm{FiO}_{2}$ ratio was also significantly correlated with our patients' prognosis: those with a favorable outcome showed a mean value in- 
dicative of acute lung injury (ALI), while in those with an unfavorable the outcome was indicative of ARDS. However, clinical trials of interest usually analyze $\mathrm{PaO}_{2}$ value recorded at patients first hospital evaluation, without any oxygen treatment.

Our 18 patients were already undergoing oxygen therapy by the territorial emergency doctor or at the emergency department before being transferred at our Internal Medicine Department.

Therefore, we considered it appropriate and more reliable to analyze the relationship $\mathrm{PaO}_{2} / \mathrm{FiO}_{2}$ rather than the effective $\mathrm{PaO}_{2}$. In our patient population finally 4 patients were submitted to NIV C-PAP and 7 patients to NIV B-PAP; the outcome of $4 / 4(100 \%)$ and $6 / 7(85.71 \%)$ patients later turned out to be unfavorable. However, there was no indication on any statistically significant correlation between respiratory support NIV and outcome. ${ }^{55-65}$

Specific treatment for PJP was administered as soon as the clinical suspicion was raised, because it has been frequently observed that a delayed treatment start, even minimal sometimes, greatly worsens the prognosis of PJP. ${ }^{66-69}$ This is related to the acute course that this infection shows in non-HIV patients, with a rapid progression to an irreversible, and thus fatal, lung damage.

We also reported the possible glucocorticoid treatment undertaken during hospitalization, after considering the evidence of improved outcomes shown in literature, when administered during the early three days of antimicrobial therapy, to HIV-positive patients with $\mathrm{PCP}$ with a $\mathrm{PaO}_{2}<70 \mathrm{mmHg}$. In our study we were administered it to $17 / 18$ patients $(94.44 \%)$, and the outcome was unfavorable revealing 12/17 (70.59\%). These data would seem to be in line with the majority of current clinical studies and have not provided any real evidence of such a benefit associated with co-treatment with glucocorticoids in HIV-negative patients.

We also analyzed the use of adjunctive drugs, consisting of caspofungin, ganciclovir and intravenous Ig. Caspofungin was administered to 13 out of 18 of patients, and the outcome turned out to be unfavorable for $9 / 13$ patients. Caspofungin, according to some literature data, could improve the prognosis of patients suffering from PCP, for its possible synergic action to TMP+SMX in killing the fungus mentioned above.

There are some case reports that suggest the effectiveness, as a salvage treatment, of adjunctive caspofungin, but the majority of clinical studies failed to recognize a benefit associated with the administration of this antifungal drug. Also, echinocandins are highly expensive: therefore, current literature does not support a routinely use of caspofungin in patients with PJP. More clinical studies will be performed in order to accurately assess utility vs cost.

Ganciclovir was given to 9/18 patients (50\%) because of their blood or BAL PCR positivity for CMV. We administered intravenous Ig to $11 / 18$ patients (61.11\%). No significant difference regarding the outcome was observed between patients who underwent ganciclovir or intravenous Ig treatment and the ones who did not. The treatment with intravenous Ig has been used successfully to prevent infection in immunocompromised rodents.

CURB-65 and PSI prognostic scores are routinely used in clinical practice to predict pneumoniaassociated mortality, regardless of patients' immune status (immunocompetent or immunocompromised). Some clinical studies in the past few years have expressed dissatisfaction with the accuracy of CURB-65 and PSI scores in predicting immunocompromised patients' outcome. In fact, these scores do not include the immune status among the parameters that correlate with the prognosis; on the other hand, it appears that immune dysfunction is associated with a much worse prognosis than that of immunocompetent patients. However, no prognostic score for immunocompromised patients with pneumonia has been yet developed. Our analysis found no significant statistical correlation between CURB-65 score and PSI risk class and our patients outcome, and despite the fact that we have considered both mortality and ICU admission as an unfavorable outcome, if the mortality rate among ICU admitted patients of nearly $60 \%$ (according to literature) is taken for granted, those prognostic scores still do not seem to be accurate in predicting PJP outcome.

The outcome turned out to be unfavorable in 12 out of 18 patients $(66.7 \%)$, thus confirming the high mortality rate in these patients reported in literature, in particular compared with immunosuppressed HIVpositive patients..$^{70-88}$

\section{Conclusions}

PJP is increasingly gaining importance as an issue of interest not only regarding the experts in infectious diseases and HIV-positive patients, due to the growing prevalence of diseases in Internal medicine ward of immunosuppressed patients non HIVpositive and to the increase in chemotherapy and biological drugs, to undermine the status of immunocompetence.

The PJP represents a current challenge for the internist who is often treating these patients in the internal medicine department, often suffering from multiple comorbidities and in which it is crucial to raise an early clinical suspicion in order to undertake a proper treatment as soon as possible. 
Those findings from our study in agreement with data reported in literature also underlined that early initiation of a specific treatment is of fundamental importance in these patients, and how time period in this particular form of pneumonia is limited. Therefore, PJP should be excluded as soon as possible and, in case of strong clinical-radiological suspicion, therapy should be started immediately, even waiting for microbiological confirmation (especially in critically ill patients).

Our statistical analysis found a significant correlation between some arterial blood gas (arterial $\mathrm{pH}$ and $\mathrm{PaCO}_{2}$ upon admission and $\mathrm{PaO}_{2} / \mathrm{FiO}_{2}$ ratio on admission), laboratory (serum LDH concentration and serum IgG upon admission) and therapeutic (elapsed time between admission and start of specific treatment) and our patients' outcome.

This last variable is the most important for the clinical practitioner, because it is the only variable where clinicians can actively intervene by significantly improving the prognosis of PJP.

Finally, the main diagnostic scores used for prognostic stratification of patients with pneumonia (CURB 65 and PSI) have not proved to be useful in our population of immunocompromised patients. The limitation of our study, like that of most of the studies conducted on this type of patients, is the low number of exponents of the population under consideration, but still high enough to become a case study observed in an internal medicine department.

It will be necessary to conduct further studies in order to accurately identify the predisposing factors to the PJP in case of HIV negativity, so as to guide the physician in early clinical suspicion and identify the main prognostic factors related to the outcome, and to optimize the treatment and reduce even high mortality associated with the increase of this disease in internal medicine departments.

\section{References}

1. Gottlieb MS, Schroff R, Schanker HM, et al. Pneumocystis carinii Pneumonia and Mucosal Candidiasis in Previously Healthy Homosexual Men - Evidence of a New Acquired Cellular Immuno-deficiency. N Engl J Med 1981;305:1425-31.

2. Kaplan JE, Hanson DL, Navin TR, Jones JL. Risk Factors for Primary Pneumocystis carinii Pneumonia in Human Immunodeficiency Virus - Infected Adolescents and Adults in the United States:Reassessment of Indications for Chemoprophylaxis. J Infect Dis 1998;178: 1126-32.

3. Haburchak DR, Bartlett J. Preventing Opportunistic Infections in Patients With HIV. Medscape Apr 28, 2014.

4. Morris A, Lundgren JD, Masur H, et al. Current Epidemiology of Pneumocystis Pneumonia. Emerg Infect Dis 2004;10:1713-20.
5. Walzer PD, Evans HE, Copas AJ, et al. Early predictors of mortality from Pneumocystis jirovecii pneumonia in HIV-infected patients: 1985-2006. Clin Infect Dis 2008;46:625-33.

6. Su YS, Lu JJ, Perng CL, Chang FY. Pneumocystis jirovecii pneumonia in patients with and without human immunodeficiency virus infection. J Microbiol Immunol Infect 2008;41:478-82.

7. Fei MW, Kim EJ, Sant CA, et al. Predicting mortality from HIV-associated Pneumocystis pneumonia at illness presentation: an observational cohort study. Thorax 2009;64:1070-6.

8. Mansharamani NG, Garland R, Delaney D, Koziel H. Management and outcome patterns for adult Pneumocystis carinii pneumonia, 1985 to 1995: comparison of HIV-associated cases to other immunocompromised states. Chest 2000;118:704-11.

9. Roblot F, Godet C, Le Moal G, et al. Analysis of underlying diseases and prognosis factors associated with Pneumocystis carinii pneumonia in immunocompromised HIV-negative patients. Eur J Clin Microbiol Infect Dis 2002;21:523-31.

10. Pagano L, Fianchi L, Mele L, et al. Pneumocystis carinii pneumonia in patients with malignant haematological diseases: 10 years' experience of infection in GIMEMA centres. Br J Haematol 2002;117:379-86.

11. Monnet X, Vidal-Petiot E, Osman D, et al. Critical care management and outcome of severe Pneumocystis pneumonia in patients with and without HIV infection. Crit Care 2008;12:R28.

12. Cooley L, Dendle C, Wolf J, et al. Consensus guidelines for diagnosis, prophylaxis and management of Pneumocystis jirovecii pneumonia in patients with haematological and solid malignancies, 2014. Intern Med J 2014;44:1350-63.

13. Carmona EM, Limper AH. Update on the diagnosis and treatment of Pneumocystis pneumonia. Ther Adv Respir Dis 2011;5:41-59.

14. Martin SI, Fishmanb JA; AST Infectious Diseases Community of Practice. Pneumocystis Pneumonia in Solid Organ Transplantation. Am J Transplant 2013;13:272-9.

15. Robberts FJ, Liebowitz LD, Chalkley LJ. Polymerase chain reaction detection of Pneumocystis jiroveci: evaluation of 9 assays. Diagn Microbiol Infect Dis 2007;58:385-92.

16. Lu Y, Ling G, Qiang C, et al. PCR diagnosis of Pneumocystis pneumonia: a bivariate meta-analysis. J Clin Microbiol 2011;49:4361-3.

17. Fillaux J, Berry A. Real-time PCR assay for the diagnosis of Pneumocystis jirovecii pneumonia. Methods Mol Biol 2013;943:159-70.

18. Saksasithon S, Sungkanuparph S, Thanakitcharu S. Pneumocystis carinii pneumonia in patients without HIV infection. J Med Assoc Thai 2003;86:612-6.

19. Roblot F, Imbert S, Godet C, et al. Risk factors analysis for Pneumocystis jiroveci pneumonia (PCP) in patients with haematological malignancies and pneumonia. Scand J Infect Dis 2004;36:848-54.

20. Lemiale V, Debrumetz A, Delannoy A, et al. Adjunctive steroid in HIV-negative patients with severe Pneumocystis pneumonia. Respir Res 2013;14:87.

21. Ko Y, Jeong BH, Park HY, et al. Outcomes of Pneu- 
mocystis pneumonia with respiratory failure in HIVnegative patients. J Crit Care 2014;29:356-61.

22. Fillatre P, Decaux O, Jouneau S, et al. Incidence of Pneumocystis jiroveci pneumonia among groups at risk in HIV-negative patients. Am J Med 2014; 127:1242.e11-7.

23. Uzuka T, Takahashi H, Tanaka R, et al. [Pneumocystis carinii pneumonia complicating brain tumor]. No Shinkei Geka 2004;32:127-33.

24. Barbounis V, Aperis G, Gambletsas E, et al. Pneumocystis carinii pneumonia in patients with solid tumors and lymphomas: predisposing factors and outcome. Anticancer Res 2005;25:651-5.

25. Yale SH, Limper AH. Pneumocystis carinii pneumonia in patients without acquired immunodeficiency syndrome: associated illness and prior corticosteroid therapy. Mayo Clin Proc 1996;71:5-13.

26. Komano Y, Harigai M, Koike R, et al. Pneumocystis jiroveci pneumonia in patients with rheumatoid arthritis treated with infliximab: a retrospective review and case-control study of 21 patients. Arthritis Rheum 2009;61:305-12.

27. Thursky KA, Worth LJ, Seymour JF, et al. Spectrum of infection, risk and recommendations for prophylaxis and screening among patients with lymphoproliferative disorders treated with alemtuzumab. Br J Haematol 2006;132:3-12.

28. Laursen A, Obel NS, Holmskov U, et al. Activation of the respiratory burst by Pneumocystis carinii. Efficiency of different antibody isotypes, complement, lung surfactant protein $\mathrm{D}$, and mannan-binding lectin. APMIS 2003;111:405-15.

29. Wells J, Haidaris CG, Wright TW, Gigliotti F. Complement and $\mathrm{Fc}$ function are required for optimal antibody prophylaxis against Pneumocystis carinii pneumonia. Infect Immun 2006;74:390-3.

30. Kamel S, O'Connor S, Lee N, et al. High incidence of Pneumocystis jirovecii pneumonia in patients receiving biweekly rituximab and cyclophosphamide, adriamycin, vincristine, and prednisone. Leuk Lymphoma 2010;51:797-801.

31. Kolstad A, Holte H, Fosså A, et al. Pneumocystis jirovecii pneumonia in B-cell lymphoma patients treated with the rituximab-CHOEP-14 regimen. Haematologica 2007;92:139-40.

32. Haeusler GM, Slavin MA, Seymour JF, et al. Lateonset Pneumocystis jirovecii pneumonia post-fludarabine, cyclophosphamide and rituximab: implications for prophylaxis. Eur J Haematol 2013;91:157-63.

33. Hardak E, Oren I, Dann EJ, et al. The increased risk for pneumocystis pneumonia in patients receiving rituximab-CHOP-14 can be prevented by the administration of trimethoprim/sulfamethoxazole: a single-center experience. Acta Haematol 2012;127:110-4

34. Tsai MJ, Chou CW, Lin FC, Chang SC. Pneumocystis jiroveci pneumonia in patients with systemic lupus erythematosus after rituximab therapy. Lupus 2012;21: 914-8.

35. Bonilla-Abadía F, Betancurt JF, Pineda JC, et al. Pneumocystis jirovecii pneumonia in two patients with systemic lupus erythematosus after rituximab therapy. Clin Rheumatol 2014;33:415-8.

36. Wright TW, Gigliotti F, Finkelstein JN, et al. Immune- mediated inflammation directly impairs pulmonary function, contributing to the pathogenesis of Pneumocystis carinii pneumonia. J Clin Invest 1999;104: 1307-17.

37. Limper AH. Alveolar macrophage and glycoprotein responses to Pneumocystis carinii. Semin Respir Infect 1998;13:339-47.

38. Wang J, Wright TW, Gigliotti F. Immune Modulation as Adjunctive Therapy for Pneumocystis pneumonia. Interdiscip Perspect Infect Dis 2011;2011:918038.

39. Mori S, Sugimoto M. Pneumocystis jirovecii infection: an emerging threat to patients with rheumatoid arthritis. Rheumatology (Oxford) 2012;51: 2120-30.

40. Wu AK, Cheng VC, Tang BS, et al. The unmasking of Pneumocystis jiroveci pneumonia during reversal of immunosuppression: case reports and literature review. BMC Infect Dis 2004;4:57.

41. Boonsarngsuk V, Sirilak S, Kiatboonsri S. Acute respiratory failure due to Pneumocystis pneumonia: outcome and prognostic factors. Int $\mathrm{J}$ Infect Dis 2009; 13:59-66.

42. Zaman MK, White DA. Serum lactate dehydrogenase levels and Pneumocystis carinii pneumonia. Diagnostic and prognostic significance. Am Rev Respir Dis 1988;137:796-800.

43. Quist J, Hill AR. Serum lactate dehydrogenase (LDH) in Pneumocystis carinii pneumonia, tuberculosis, and bacterial pneumonia. Chest 1995;108:415-8.

44. Butt AA, Michaels S, Kissinger P. The association of serum lactate dehydrogenase level with selected opportunistic infections and HIV progression. Int J Infect Dis 2002;6:178-81.

45. Vogel M, Weissgerber P, Goeppert B, et al. Accuracy of serum LDH elevation for the diagnosis of Pneumocystis jiroveci pneumonia. Swiss Med Wkly 2011;141: w13184.

46. Fernandez P, Torres A, Miro JM, et al. Prognostic factors influencing the outcome in pneumocystis carinii pneumonia in patients with AIDS. Thorax. 1995;50: 668-71.

47. Antinori A, Maiuro G, Pallavicini F, et al. Prognostic factors of early fatal outcome and long-term survival in patients with Pneumocystis carinii pneumonia and acquired immunodeficiency syndrome. Eur J Epidemiol 1993;9:183-9.

48. Laursen AL, Andersen PL. Low levels of IgG antibodies against pneumocystis carinii among HIV-infected patients. Scand J Infect Dis 1998;30:495-9.

49. Djawe K, Huang L, Daly KL, et al. Serum Antibody Levels to the Pneumocystis jirovecii Major Surface Glycoprotein in the Diagnosis of P. jirovecii Pneumonia in HIV+ Patients. PLoS One 2010;5:e14259.

50. Jalil A, Moja P, Lambert C, et al. Decreased Production of Local Immunoglobulin A to Pneumocystis carinii in Bronchoalveolar Lavage Fluid from Human Immunodeficiency Virus-Positive Patients. Infect Immun 2000;68:1054-60.

51. Zamora MR. Cytomegalovirus and Lung Transplantation. Am J Transplant 2004;4:1219-26.

52. Razonable RR, Humar A. Cytomegalovirus in solid organ transplant recipients-Guidelines of the American Society of Transplantation Infectious Diseases Community of Practice. Clin Transplant 2019;33:e13512. 
53. Kim SJ, Lee J, Cho YJ, et al. Prognostic factors of Pneumocystis jirovecii pneumonia in patients without HIV infection. J Infect 2014;69:88-95.

54. Benfield TL, Helweg-Larsen J, Bang D, et al. Prognostic markers of short-term mortality in AIDS-associated Pneumocystis carinii pneumonia. Chest 2001;119: 844-51.

55. Crans CA Jr, Boiselle PM. Imaging features of Pneumocystis carinii pneumonia. Crit Rev Diagn Imaging 1999;40:251-84.

56. Boiselle PM, Crans CA Jr, Kaplan MA. The changing face of Pneumocystis carinii pneumonia in AIDS patients. AJR Am J Roentgenol 1999;172:1301-9.

57. Bollée G, Sarfati C, Thiéry G, et al. Clinical picture of Pneumocystis jiroveci pneumonia in cancer patients. Chest 2007;132:1305-10.

58. Vogel MN, Vatlach M, Weissgerber P, et al. HRCT-features of Pneumocystis jiroveci pneumonia and their evolution before and after treatment in non-HIV immunocompromised patients. Eur J Radiol 2012;81: 1315-20.

59. Kanne JP, Yandow DR, Meyer CA. Pneumocystis jiroveci pneumonia: high-resolution CT findings in patients with and without HIV infection. AJR Am J Roentgenol 2012;198:W555-61.

60. Hartman TE, Primack SL, Muller NL, Staples CA. Diagnosis of thoracic complications in AIDS: accuracy of CT. AJR Am J Roentgenol 1994;162:547-53.

61. Kuhlman JE. Pneumocystic infections: the radiologist's perspective. Radiology 1996;198:623-35.

62. Hidalgo A, Falcó V, Mauleón S, et al. Accuracy of high-resolution CT in distinguishing between Pneumocystis carinii pneumonia and non- Pneumocystis carinii pneumonia in AIDS patients. Eur Radiol 2003;13: 1179-84.

63. Fujii T, Nakamura T, Iwamoto A. Pneumocystis pneumonia in patients with HIV infection: clinical manifestations, laboratory findings, and radiological features. J Infect Chemother 2007;13:1-7.

64. Consensus statement on the use of corticosteroids as adjunctive therapy for pneumocystis pneumonia in the acquired immunodeficiency syndrome. The National Institutes of Health-University of California Expert Panel for Corticosteroids as Adjunctive Therapy for Pneumocystis Pneumonia. N Engl J Med 1990;323: 1500-4.

65. Vilar FJ, Khoo SH, Walley T. The management of Pneumocystis carinii pneumonia. Br J Clin Pharmacol 1999;47:605-9.

66. Overgaard UM, Helweg-Larsen J. Pneumocystis jiroveci pneumonia (PCP) in HIV-1-negative patients: a retrospective study 2002-2004. Scand J Infect Dis 2007;39:589-95.

67. Vidal S, De la Horra C, Martin J, et al. Pneumocystis jirovecii colonisation in patients with interstitial lung disease. Clin Mmicrobiol Infect 2006;12:231-5.

68. Matsumura Y, Shindo Y, Iinuma Y, et al. Clinical characteristics of Pneumocystis pneumonia in non-HIV patients and prognostic factors including microbiological genotypes. BMC Infect Dis 2011;11:76.

69. Li MC, Lee NY, Lee CC, et al. Pneumocystis jiroveci pneumonia in immunocompromised patients: delayed diagnosis and poor outcomes in non-HIV-infected in- dividuals. J Microbiol Immunol Infect 2014;47: 42-7.

70. Montaner JS, Lawson LM, Levitt N, et al. Corticosteroids prevent early deterioration in patients with moderately severe Pneumocystis carinii pneumonia and the acquired immunodeficiency syndrome (AIDS). Ann Intern Med 1990;113:14-20.

71. Delclaux C, Zahar JR, Amraoui G, et al. Corticosteroids as adjunctive therapy for severe Pneumocystis carinii pneumonia in non-human immunodeficiency virus-infected patients: retrospective study of 31 patients. Clin Infect Dis 1999;29:670-2.

72. Moon SM, Kim T, Sung H, et al. Outcomes of moderate-to-severe Pneumocystis pneumonia treated with adjunctive steroid in non-HIV-infected patients. Antimicrob Agents Chemother 2011;55:4613-8.

73. Lemiale V, Debrumetz A, Delannoy A, et al. Adjunctive steroid in HIV-negative patients with severe Pneumocystis pneumonia. Respir Res 2013;14:87.

74. Pareja JG, Garland R, Koziel H. Use of adjunctive corticosteroids in severe adult non-HIV Pneumocystis carinii pneumonia. Chest 1998;113:1215-24.

75. Mu XD, Que CL, He B, et al. Caspofungin in salvage treatment of severe pneumocystis pneumonia: case report and literature review. Chin Med J (Engl) 2009; 122:996-9.

76. Kim T, Hong HL, Lee YM, et al. Is caspofungin really an effective treatment for Pneumocystis jirovecii pneumonia in immunocompromised patients without human immunodeficiency virus infection? Experiences at a single center and a literature review. Scand J Infect Dis 2013;45:484-8.

77. Kamboj M, Weinstock D, Sepkowitz KA. Progression of Pneumocystis jiroveci pneumonia in patients receiving echinocandin therapy. Clin Infect Dis 2006;43: e92-4.

78. Respaldiza N, Medrano FJ, Medrano AC, et al. High seroprevalence of Pneumocystis infection in Spanish children. Clin Microbiol Infect 2004;10:1029-31.

79. Medrano FJ, Respaldiza N, Medrano A, et al. Seroprevalence of Pneumocystis human infection in southern Spain. J Eukaryot Microbiol 2003;50:649-50.

80. Vargas SL, Hughes WT, Santolaya ME, et al. Search for primary infection by Pneumocystis carinii in a cohort of normal, healthy infants. Clin Infect Dis 2001; 32:855-61.

81. Peglow SL, Smulian GA, Linke MJ, et al. Serologic responses to specific Pneumocystis carinii antigens in health and disease. J Infect Dis 1990;161:296-306.

82. Roths JB, Sidman CL. Single and combined humoral and cell-mediated immunotherapy of Pneumocystis carinii pneumonia in immunodeficient scid mice. Infect Immun 1993;61:1641-9.

83. Lee M, Cho SR, Park YK, et al. The effect of heterogeneous hyperimmune $\mathrm{IgG}$ antibody on prophylaxis and treatment of Pneumocystis carinii infection in rats. Korean J Parasitol 1998;36:127-32.

84. Wang $\mathrm{CH}$, Chan ED, Perng CL, et al. Intravenous immunoglobulin replacement therapy to prevent pulmonary infection in a patient with Good's syndrome. J Microbiol Immunol Infect 2015;48:229-32.

85. Papakonstantinou I, Baraboutis IG, Karnesis L. Late Onset Combined Immunodeficiency Presenting with 
Recurrent Pneumocystis jiroveci Pneumonia. Case Rep Med 2014;2014:801-5.

86. Sanders KM, Marras TK, Chan CKN. Pneumonia severity index in the immunocompromised. Can Respir J 2006;13:89-93.

87. Gonzalez C, Johnson T, Rolston K, et al. Predicting pneumonia mortality using CURB-65, PSI, and patient characteristics in patients presenting to the emergency department of a comprehensive cancer center. Cancer Med 2014;3:962-70.

88. Carrabba M, Zarantonello M, Bonara P, et al. Severity assessment of healthcare-associated pneumonia and pneumonia in immunosuppression. Eur Respir J 2012;40:1201-10. 